\title{
Modeling of a Permanent Magnet Synchronous Generator in a Power Wind Generation System with an Electrochemical Energy Storage
}

\author{
Abdelhakim BELKAID ${ }^{\mathrm{a}, \mathrm{b}}$, Ilhami COLAK ${ }^{\mathrm{c},}$, Korhan $\mathrm{KAYISLI}^{\mathrm{c}}$, Ramazan BAYINDIR ${ }^{\mathrm{d},}$
}

belkaid08@yahoo.fr; ilhcol@gmail.com; korhankayisli@gmail.com; bayindir@gazi.edu.tr

\author{
${ }^{a}$ Department of Electromechanics, University of BordjBouArreridj, El-Anasser 34030, \\ BordjBouArreridj, Algeria \\ ${ }^{b}$ Automatic Laboratory of Setif (LAS), University of Setif 1, El Maabouda, Street of Bejaia, 19000 Setif, Algeria \\ ${ }^{c}$ Engineering and Architecture Faculty of Nisantasi University, Istanbul, Turkey \\ ${ }^{d}$ Department of Electrical \& Electronics Engineering, Gazi University, Faculty of Technology, 06500, Turkey
}

\begin{abstract}
With the development of power electronics, directly driven permanent magnet synchronous generators (PMSGs) have attracted increasing interest from wind turbine (WT) producers because of their benefits over other variable speed WTs. PMSGs have a big number of poles and competitive costs. In this article simplified model and real modeling of a small power wind conversion system are offered. The system consists on a horizontal axis WT, PMSG, diodes rectifier, and a low voltage lead-acid battery. The models implemented in the Matlab-Simulink software can reflect the real physical phenomena. A longer calculation time is required when adopting the detailed model compared to the simplified model. The results of the simulation demonstrate that the suggested simplified model has enough precision to analyze the dynamics of the WT system.
\end{abstract}

Index Terms-modeling, wind turbine, PMSG, simplified model.

\section{INTRODUCTION}

Global energy consumption has augmented dramatically these last years, because of the huge industrialization, which tends to increase more and more. The risks of fossil fuel depletion and their effects on weather change once again underline the importance of using renewable energy [1]. Among these, we meet the wind energy that has experienced strong growth and has become competitive through the developing of the wind turbine manufacturing, and the advances in semiconductor technology, as well as novel methodologies of turbine control at variable speeds. Nevertheless, several problems encountered, related on the one hand to the complication of wind energy conversion schemes; that is, the need for the gearbox between the turbine and the generator, and the instability of the wind speed on the other hand [2-4]. The use of well-designed wind structures, such as the high-pole PMSG, makes variable-speed wind turbine conversion systems more attractive than fixed-speed wind turbine systems because of the possibility of optimal power for diverse wind speeds, and reduced mechanical stress by eliminating the gear box, which enhances the reliability of the system, and reduced maintenance costs. [2,5]. Electrical systems in wind energy conversion can be subdivided into several main groups.
Fixed speed systems use inductive generators connected directly to the network. Variable speed electrical systems use asynchronous machines, synchronous machines or unconventional machines. These are complicated and are all equipped with electronic converters. The chains of conversion of small power (some $100 \mathrm{~W}$ ) and those of large power (more than $40 \mathrm{~kW}$ ) are then very different. Either in isolated sites of small power or in systems connected to the network (also in small power), an intermediate DC bus is used before transforming the energy into alternating current. In the case of very small powers, the energy is directly consumed in direct current. The continuous bus has the advantage of more easily interconnecting various production systems (wind, photovoltaic, diesel, fuel cell, etc.) and electrochemical batteries that can be directly buffered on such buses. Such systems are called hybrid. The use of wind energy for the production of electrical energy is booming. The category of small wind turbines from 1 to $100 \mathrm{~kW}$ mainly owes its development generally in hybrid windphotovoltaic or wind-diesel applications. Small power conversion chains are mainly for isolated sites. They are based on the use of a permanent magnet synchronous machine, which flows directly through a diode rectifier into a generally low voltage electrochemical accumulator (12 to $48 \mathrm{~V}$ ). This configuration allows direct drive without speed multiplier and still connected directly to a diode rectifier. It has a reduced cost and fewer losses [6]. The ultimate goal is to contribute to the study of a hybrid wind and photovoltaic conversion chain with an electrochemical accumulator. In this paper, after a theoretical description of the characteristics of wind turbines, we propose a mathematical modeling of the wind energy system. The model is validated by numerical simulation via Matlab/Simulink software.

The rest of the document is intended as follows; the second part gives the description of the studied system; followed by characteristics of the wind turbine in the third part; simplified model and real modeling of the global wind conversion system are offered respectively in part 4 and 5; the sixth part analyzes and comments on the results of the simulation. Finally, in the seventh part, conclusions and perspectives are proposed. 


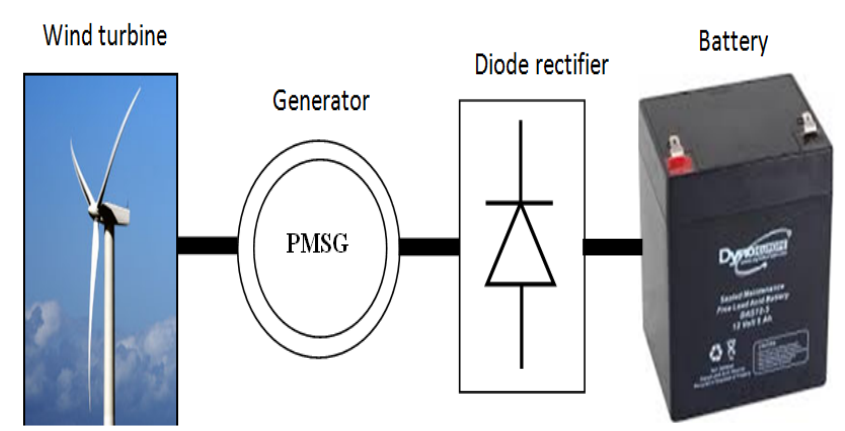

Fig. 1 Magnet wind turbine delivering directly through a diode bridge on the continuous bus

\section{STUDIED WIND SYSTEM}

In this work, we are particularly interested in the wind energy conversion chain. Fig. 1 illustrates the system to be studied, consisting of a high-number of poles of PMSG, which flows directly through a three-phase diode bridge to the DC bus and the electrochemical accumulator. The direct flow of the synchronous machine on a DC voltage source through a simple diode bridge rectifier may surprise. A rectifier operating on a DC voltage source must be powered by an AC power source [7]. In fact, it is thanks to the high value of the armature inductance that the currents remain close to the sinusoidal forms and that the conversion efficiencies are correct. If the battery is overloaded (too much voltage), a contactor short-circuits the generator armature. The turbine is then stopped in rotation.

\section{CHARACTERISTICS OF THE WIND TURBINE}

The total kinetic power $P_{w}$ of the wind through a disk of radius $R$ is given by the following relation [4,8-9]:

$$
P_{w}=\frac{1}{2} \rho \pi R^{2} V_{w}^{3}
$$

where $\rho$ is the density of the air $(\rho=1.225 \mathrm{~kg} / \mathrm{m}), V_{w}$ is the wind speed and $R$ practically corresponds to the length of the blade.

A fraction of this power is captured by the wind turbine. It is characterized by a factor $C_{P}(\lambda, \beta)$, called coefficient of performance or power coefficient. This coefficient, which cannot exceed the value of $16 / 27$ (Betz limit) due to aerodynamic and mechanical losses, depends on two parameters $\lambda$ and $\beta$ as expressed in [10-11] by (2) and (3).

$$
\begin{aligned}
& C_{P}(\lambda, \beta)=c_{1} \cdot\left(\frac{c_{2}}{\lambda_{i}}-c_{3} \cdot \beta-c_{4}\right) \cdot e^{-\frac{c_{5}}{\lambda_{i}}}+c_{6} \cdot \lambda \\
& \frac{1}{\lambda_{i}}=\frac{1}{\lambda+0.08 \cdot \beta}-\frac{0.035}{1+\beta^{3}}
\end{aligned}
$$

The parameters of $\mathrm{c} 1$ to $\mathrm{c} 6$ are: $\mathrm{c}_{1}=0.5176, \mathrm{c}_{2}=116, \mathrm{c}_{3}=0.4$, $\mathrm{c}_{4}=5, \mathrm{c}_{5}=21, \mathrm{c}_{6}=0.0068$.
The $\mathrm{p} 26-132-1-C E$.docxarameter $\lambda$ is the ratio between the linear speed of the blade tips on the wind speed, is known as tip speed ratio (TSR) and the second parameteris known as blade pitch angle. Fig. 2shows the evolution of $C_{p}$ in function of $\lambda$ for different $\beta$. It can be seen that when $\beta=0^{\circ}$ the optimal point corresponds to the couple of ( $\lambda_{\text {opt }}=8.1 \& C_{p \max }=0.48$ ).

The mechanical power $P_{\text {turbine }}$ harvested by the wind turbine can be expressed as:

$$
\begin{aligned}
& P_{\text {turbine }}=C_{p}(\lambda) \cdot P_{w} \\
& \lambda=\frac{\Omega_{\text {turbine }} \cdot R}{V_{w}}
\end{aligned}
$$

where $\Omega_{\text {turbine }}$ is the angular rotation speed of the turbine.

The characteristic $C_{p}(\lambda)$ provided by the turbine manufacturer, being of parabolic shape, admits a maximum $C_{p \max }$ for $\lambda_{o p t}$ as illustrated in Fig. 2. For $V_{w}$ given, corresponds a rotation speed which gives $\lambda_{o p t}$ and consequently, the power Max:

$$
P_{\text {turbine } \max }=C_{p \max } \cdot \frac{1}{2} \rho \pi R^{2} V_{w}^{3}=k \cdot V_{w}^{3}
$$

where $k$ is a constant.

Fig. 3 illustrates the theoretical characteristic of the turbine.

The wind turbine cannot operate either below a speed $V_{\min }$ called «threshold speed or cut-in speed», or beyond a speed $V_{\max }$ called "maximum speed or cut-out speed".The characteristic of the wind turbine shows us four distinct operating zones:

Zone I $\left(V_{W}<V_{\min }\right)$ : the turbine does not work;

Zone II ( $V_{\min }<V_{W}<V_{n}$ ): the power supplied depends on the wind speed, where $V_{n}$ is the wind speed with which the turbine reaches its nominal power;

Zone III $\left(V_{n}<V_{W}<V_{\max }\right)$ : the production is limited because the generator is always at its maximum power;

Zone IV $\left(V_{\max }<V_{W}\right)$ : the turbine is stopped to avoid the risks that a strong wind can bring.

The wind turbine considered in this study is composed of three blades like the one known as the Danish design. Knowing its characteristics, we have drawn a family of curves describing the mechanical power available on the rotor of the machine according to its speed of rotation for different wind speeds, as well as an operating characteristic which links the maximum mechanical powers corresponding to the various wind speeds, as illustrated in Fig. 4. The red curve shows the maximums. For this turbine, the maximum power coefficient is reached for $\lambda_{\text {opt }}=8.1$; that is to say the peripheral speed at the end of the blade equals 8 times the 
wind speed.

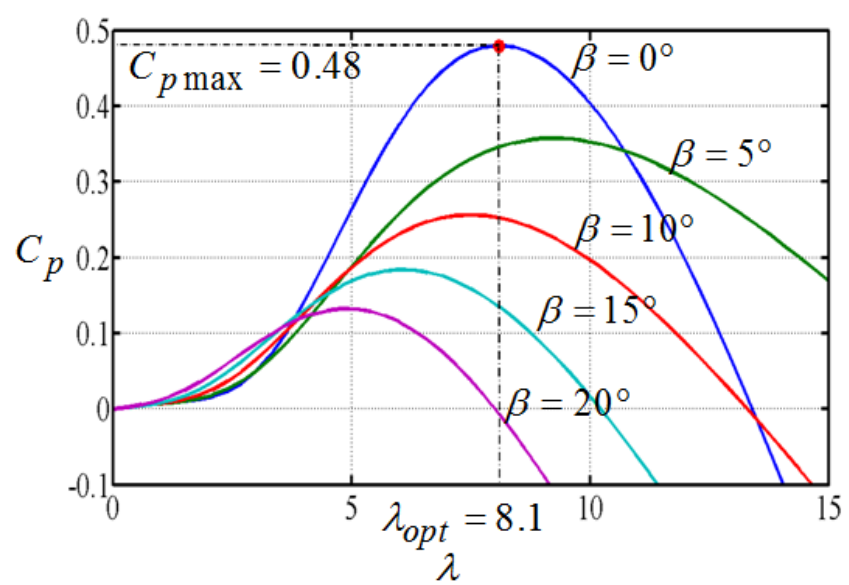

Fig. 2 Variation of $C_{p}$ in function of $\lambda$ for different $\beta$.

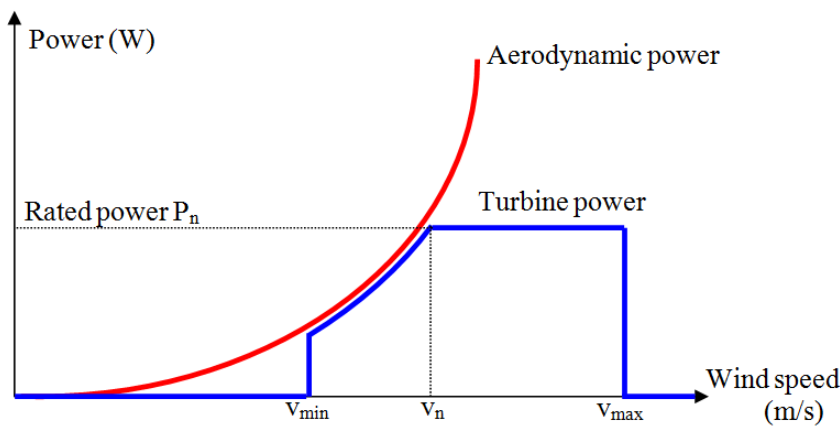

Fig. 3 Typical wind turbine power characteristic

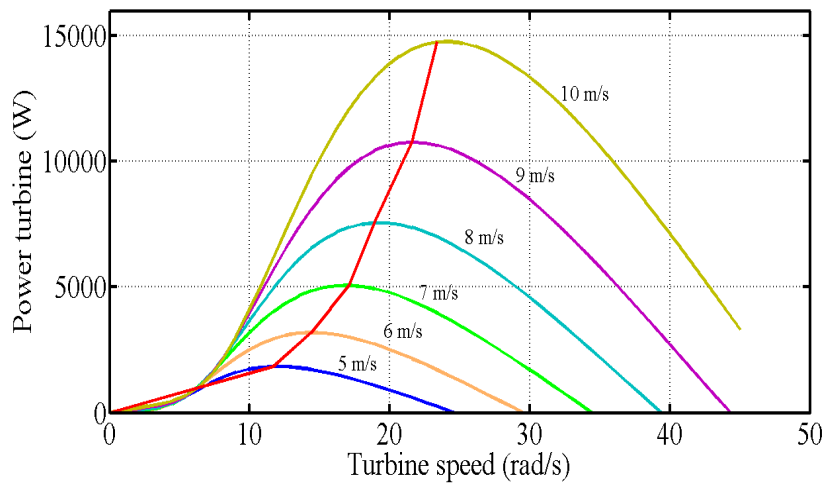

Fig. 4 Turbine power according to its rotation speed, parametrized in wind speed.The optimal operation is designated by the curve in red.

\section{SIMPLIFIED MODEL OF THE ELECTRIC CONVERSION CHAIN}

The simplified model of this wind energy chain is obtained by considering the battery of electrochemical accumulators as a perfectly constant voltage source. However, a static converter cannot connect two sources of the same nature. Therefore, the model used for the PMSG consists of a voltage source linked in series with a resistor and an inductance. The simplified electrical system is as in Fig. 5.

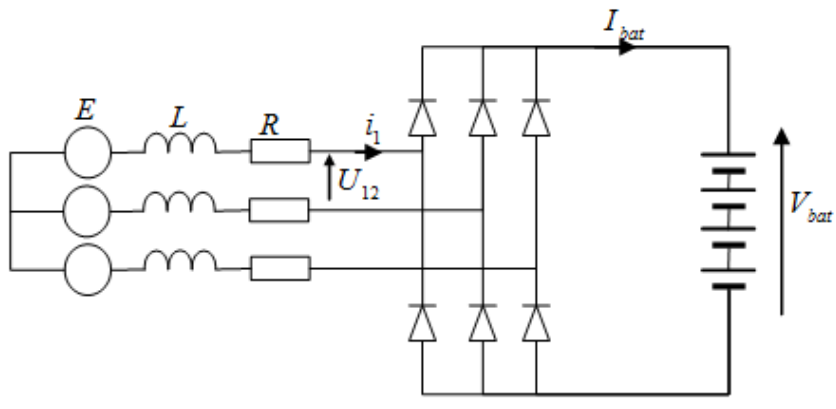

Fig. 5 Simplified model of the electrical conversion chain

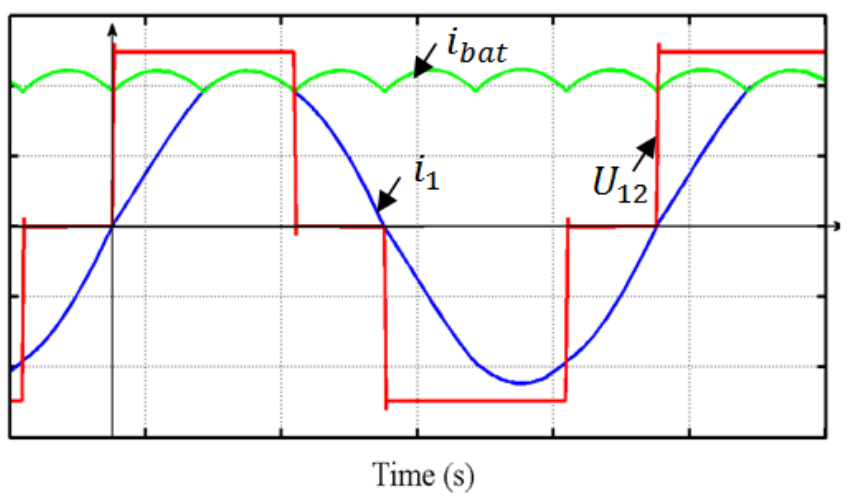

Fig. 6 Waveforms of some quantities using the simplified model: voltage $U_{12}$, current $i_{1}$ and the rectified current $I_{b a t}$.

Fig. 6 shows the waveforms of the different quantities of this simplified study. The generator behaves like a current source, it delivers perfectly sinusoidal currents $i_{1}$. The current in the battery $I_{b a t}$ is formed of six portions of sinusoid per period. The phase-to-phase voltage $U_{12}$ is rectangular in shape having three levels $+V_{b a t},-V_{b a t}$ and zero. This last value means that a short-circuit between phases is applied due to the simultaneous conduction of the diodes due to the overlaps of the phases.

\section{REAL MODELLING OF THE ELECTRIC CONVERSION CHAIN}

In this part, we go from simplified study to real modeling that takes into account the actual waveforms of currents.

\subsection{Model of transmission elements}

The fundamental principle of dynamics is governed by the expression of electromagnetic torque $T_{e m}$ :

$T_{e m}-T_{m}=J \cdot \frac{d \Omega}{d t}+F \Omega$

Where $T_{m}$ is the mechanical torque applied on the generator shaft and $F, J$ are respectively the coefficient of friction and the total moment of inertia of the system. This relationship makes it possible to determine the speed of rotation of the machine. 


\subsection{Model of PMSG}

The coupling of magnet generators with power electronics becomes increasingly economically feasible, making them a serious contestant of asynchronous double-feed generators. Systems of this type have a failure rate that is considered low due to the elimination of certain sources of faults: suppression of the speed multiplier and the system of rings and brushes. The maintenance costs are then minimized which is very interesting in wind applications. The obligatory presence of the power electronics finally allows a simple regulation of the speed of rotation and thus an efficient energy optimization.

The model of the PMSG is based on the following equations:

$v_{d}=-R_{s} \cdot i_{d}-\omega \cdot \phi_{q}-\left(L_{l s}+L_{m d}\right) \frac{d i_{d}}{d t}+L_{m d} \cdot \frac{d i_{f d}}{d t}+L_{m d} \cdot \frac{d i_{k d}}{d t}$

$v_{q}=-R_{s} \cdot i_{q}+\omega \cdot \phi_{q}-\left(L_{l s}+L_{m q}\right) \cdot \frac{d i q}{d t}+L_{m q} \cdot \frac{d i_{k q}}{d t}$

$\varphi_{d}=-\left(L_{l s}+L_{m d}\right) \cdot i_{d}+L_{m d} \cdot\left(i_{f d}+i_{k d}\right)$

$\varphi q=-\left(L_{l s}+L_{m q}\right) \cdot i q+L_{m q} \cdot i_{k q}$

where :

$v_{q}, v_{d}:$ the quadrature and direct voltages;

$i_{q}, i_{d}$ : the quadrature and direct currents;

$i_{k d}, i_{k q}:$ currents in the windings $\mathrm{kd}$, kq (reduced to the stator);

$\varphi_{d}, \varphi_{q}:$ total stator fluxes in axes d, q;

$R_{s}:$ the resistance of a stator phase;

$L_{l s}$ : leakage inductance of a stator phase;

$L_{m d}, L_{m q}$ : mutual inductances along the axes d, q;

Equations of damping windings

$$
\begin{aligned}
& 0=R_{k d} \cdot i_{k d}-L_{m d} \cdot \frac{d i_{d}}{d t}+L_{m d} \cdot \frac{d i_{f d}}{d t}+\left(L_{l k d}+L_{m d}\right) \cdot \frac{d i_{k d}}{d t} \\
& 0=R_{k q} \cdot i_{k q}-L_{m q} \cdot \frac{d i q}{d t}+\left(L_{l k q}+L_{m q}\right) \cdot \frac{d i_{k q}}{d t}
\end{aligned}
$$

where:

$R_{k d}, R_{k q}$ : resistances of windings $\mathrm{kd}$ and $\mathrm{kq}$

$L_{l k d}, L_{l k q}:$ inductances of windings $\mathrm{kd}$ and $\mathrm{kq}$

The expression of the electromagnetic torque is given by:

$$
T_{e m}=\frac{3}{2} \cdot p \cdot\left(\varphi_{d} \cdot i_{q}-\varphi_{q} \cdot i_{d}\right)
$$

where $p$ is the number of pairs of poles

\subsection{Static converter}

The static converter used in this study is a diode bridge rectifier shown in Fig. 7. Its Simulink model is depicted in Fig. 8. It is governed by the following equations:

$$
\begin{aligned}
& I_{b a t}=\frac{3}{\pi} \sqrt{6} \cdot I \\
& U_{12}=\sqrt{\frac{2}{3}} \cdot V_{b a t}
\end{aligned}
$$

$I \mathrm{rms}$ of the phase current

$U_{12}$ rms of the phase to phase voltage

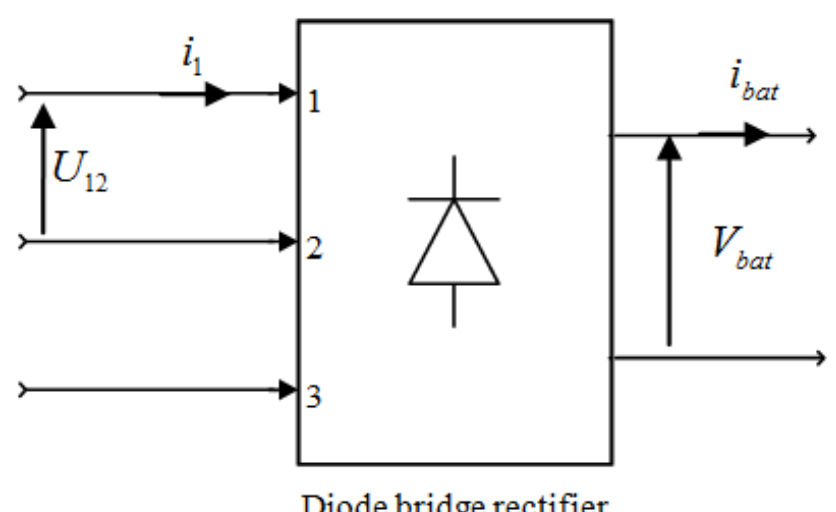

Fig. 7 Diode bridge rectifier

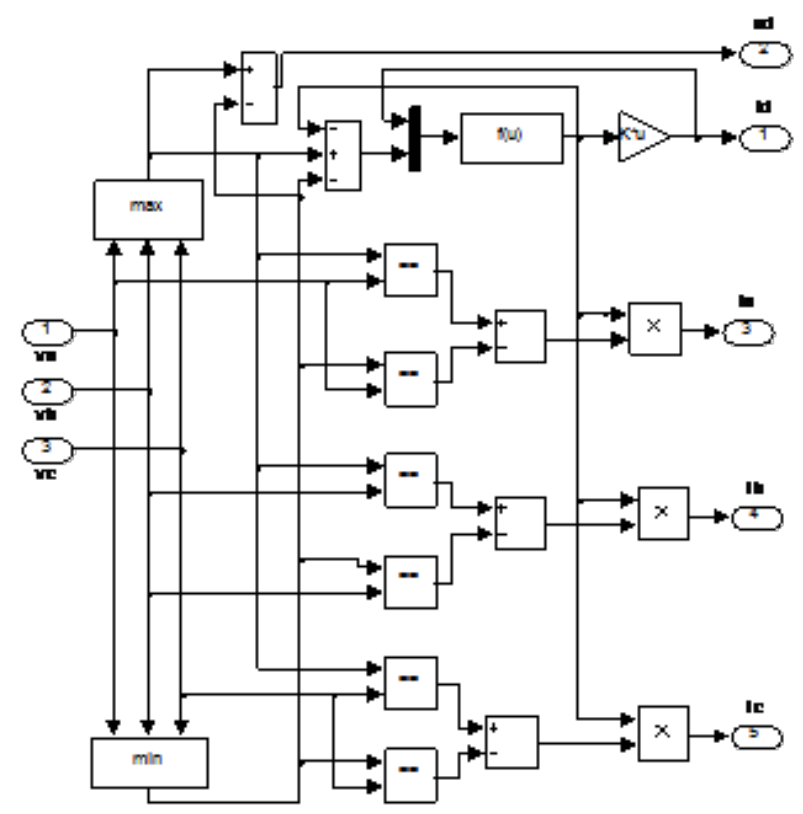

Fig. 8 Simulink model of the diode bridge

\section{SIMULATION RESULTS AND INTERPRETATIONS}

We have simulated the wind energy conversion system above for two different cases:

- The first case, for an operating point where the conduction is continuous. The waveforms of the phase current and the phase-to-phase voltage are shown in Fig. 9. At this point of operation, it can be seen that the current is quasi-sinusoidal because the amplitude of the electromotive forces of the 
generator is sufficient to allow continuous conduction.

(a)

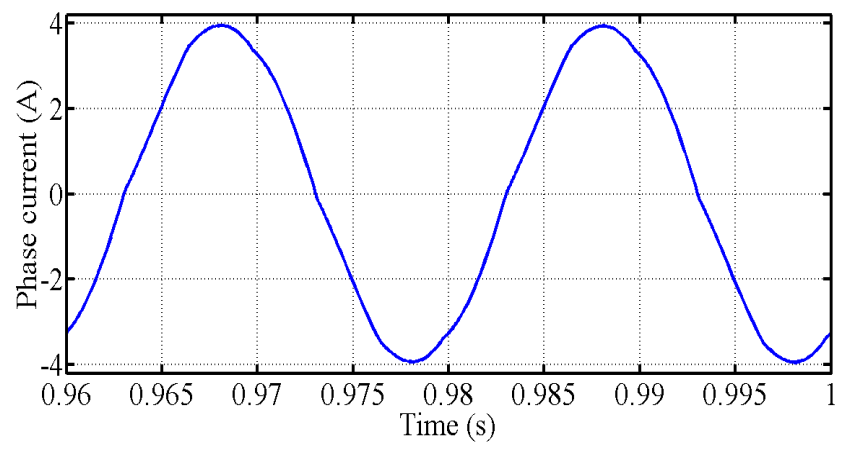

(b)

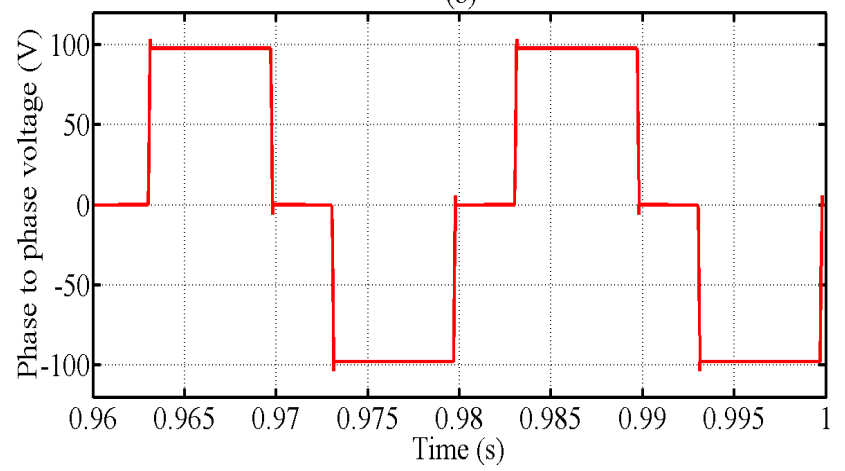

Fig. 9 Waveforms of the phase current (a) and the phase-to-phase voltage (b) in the case of continuous conduction.

(a)

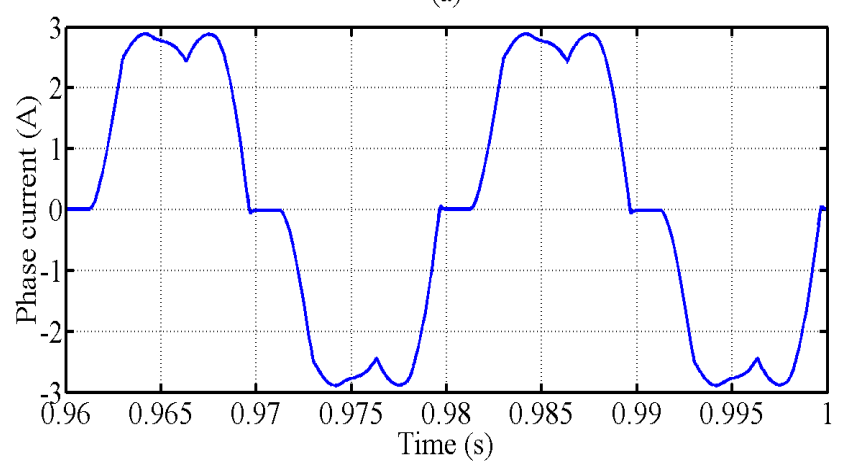

(b)

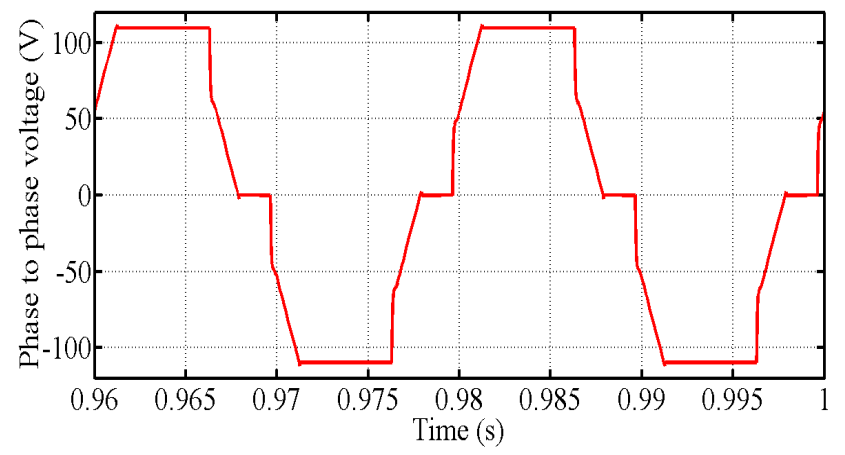

Fig. 10 Waveforms of the phase current (a) and the phase-to-phase voltage (b) in the case of discontinuous conduction.
- The second case, for an operating point where the electromotive force is not sufficient for continuous conduction. The waveforms of the same quantities are shown in Fig. 10. At this stage of operation, we can see that the current is non-sinusoidal and that the voltage is not really rectangular.

Finally, there is an approach in the simulation results between the simplified analysis and the actual modeling.

In perspective, this wind system of modest power can be used to feed loads continuously. However, it is equipped with a continuous bus. Then, we can connect it with the electricity network by means of an inverter as we can add other chains; for example a photovoltaic chain or a diesel generator.

\section{CONCLUSION}

A simplified study and a real modeling of the permanent magnet WT generator were proposed in this article. Due to the fact that the field trials are not available, a comparison of simulation results using the Matlab-Simulink software with those provided by the simplified method was used. The results are close for both methods and the models are valid. So, the offered simplified model can be utilized efficiently to analyze the WT power system since its precision is enough and the time of simulation is reduced.

In the future, this conversion chain will be extended to connect other systems such as solar panels or diesel generators and even consider the possibility of transferring excess electricity to the grid.

\section{ACKNOWLEDGMENTS}

The work reported in this paper has been supported by the CNEPRU research project No. A01L07UN340120150001, conducted at the electromechanical department, Faculty of Science and Technology, Bordj Bou Arreridj University, Algeria. This work was also supported in part by the Engineering and Architecture Faculty of Nisantasi University, Istanbul, Turkey. This support is gratefully acknowledged.

\section{REFERENCES}

[1] Niu T, Wang J, Lu H, Du P. Uncertainty modeling for chaotic time series based on optimal multi-input multi-output architecture: Application to offshore wind speed. Energy Convers Manage 2018;156:597-617.

[2] M. Chinchilla, S. Arnaltes, J. Carlos Burgos, « Control of PermanentMagnet Generators Applied to Variable-Speed Wind-Energy Systems Connected to the Grid », IEEE Transaction on energy conversion, vol 21, n 1, pp. 130-135, 2006.

[3] A. Bouscayrol, P. Delarue, X. Guillaud, "Power strategies for maximum control structure of a wind energy conversion system with a synchronous machine”, Renewable Energy 30 (2005)2273-2288.

[4] Youssef KRIM et al., "Control of a Wind Farm Connected to the Grid at a Frequency and Variable Voltage”, Int. J. Renew. Energ. Res., vol. 6, n⿳3 3,pp. 747-758, 2016.

[5] S. Morimoto ; H. Nakayama ; M. Sanada ; Y. Takeda, « Sensorless output maximization control for variable-speed wind generation system using IPMSG », IEEE Transaction on Industry Applications, vol 41, $\mathrm{n}^{\circ} 1$, pp. 60-67, 2005.

[6] O. Carlson, A. Grauers, J. Svensson, A. Larsson, «A comparison of electrical systems for variable speed operation of wind turbines », 
International Journal of Smart Grid

Belkaid et al., Vol.2, No.4, December, 2018

European Wind Energy Association Conference and Exhibition (EWEC'94) Thessaloniki, Greece, 10-14 October 1994, pp.500-505.

[7] S. Bandyopadhyay, A. P. Chandrakasan, "Platform Architecture for Solar, Thermal, and Vibration Energy Combining With MPPT and Single Inductor", IEEE journal of solid-state circuits, 47(9), SEPTEMBER 2012, pp. 2199-2215, doi:10.1109/jssc.2012.2197239

[8] Masmoudi A, Abdelkafi A, Krichen L. "Electric power generation based on variable speed wind turbine under load disturbance". Energy, 36(8), pp. 5016-5026, 2011.

[9] E. Mahersi, A. Khedher, M.F. Mimouni, "The Wind energy Conversion System Using PMSG Controlled by Vector Control and SMC Strategies", Int. J. Renew. Energ. Res., vol. 3, n 1, pp. 41-50, 2013.

[10] Shailendra Kumar Tiwari ; Bhim Singh ; Puneet Kr. Goel, «Design and Control of Autonomous Wind-Solar System With DFIG Feeding 3-Phase 4-Wire Loads ", IEEE Transaction on Industry Applications, vol 54, n², pp. 1119-1127, 2018.

[11] M. Q. Duong, F. Grimaccia, S. Leva, M.Mussetta, E. Ogliari, "Pitch Angle Control Using Hybrid Controller for All Operating Regions of SCIG Wind Turbine System", Renewable Energy, vol. 70, pp. 197 203, 2014. 